\title{
Investigación y cirugía
}

\author{
García Barreno P. \\ Departamento de Cirugía, Facultad de Medicina. Hospital General Universitario Gregorio Marañón. \\ Universidad Complutense. Madrid.
}

Actas Urol Esp. 2008;32(1):3-23

\section{RESUMEN}

\section{INVESTIGACIÓN Y CIRUGÍA}

A partir de la Segunda Guerra Mundial se ha producido un desarrollo sin precedentes en la ciencia y en la práctica médico-quirúrgicas: antibióticos, bancos de sangre, cirugía cardiaca, órganos artificiales, trasplante de órganos y de tejidos, reemplazamiento articular completo, alimentación parenteral total o cirugía mínimamente invasiva. Paradójicamente, durante las últimas dos décadas del siglo pasado, la apreciación pública de los médicos ha disminuido, a la vez que ha tenido lugar una serie de distorsiones: escalada de costes en la atención de la salud, cuestionamiento de los centros médicos académicos, pleitos por errores médicos o alza de las medicinas alternativas. La creciente complejidad de la investigación biomédica en la era continuamente cambiante de la biología molecular, ha promovido una actitud de escepticismo respecto a si los clínicos y en especial los cirujanos, pueden seguir contribuyendo a los avances médicos. El estudio de la historia de la medicina contemporánea pone de manifiesto que varios de los logros más significativos se deben a cirujanos. No cabe duda de que la ciencia y la clínica sabrán acomodarse a estos tiempos de cambio y continuarán generando importantes hallazgos. La práctica médico-quirúrgica de hoy está determinada por la investigación científica de ayer; mañana no será diferente.

Palabras clave: Gestión médica. Medicina académica. Tecnología médica. Transferencia tecnológica.

\section{ABSTRACT \\ RESEARCH AND SURGERY}

From the Second World War onwards an amazing development in science and clinical \& surgery practice has taken place: antibiotics, blood storage, cardiac surgery, organ and tissue transplant, complete joint replacement, total intravenous nutrition or minimally invasive surgery. Paradoxically, during the last two decades of the XXth century, social popularity of doctors has decreased at the same time of some important changes: increases in costs of medical attention, trials against medical mistakes, some doubts on the real role of Academic Public Hospitals and rising in the importance of alternative medicine. Increasing complexity of biomedical research in the continuous changing age of molecular biology has promoted an increasing scepticism regarding clinics and surgeons are able to keep on contributing to medical advances. The study of the contemporaneous History of Medicine demonstrates that some of the more significant achievements have been accomplished by surgeons. Undoubtedly Science and Clinics must get adapted to these times of change and persist in generating important findings. Current Clinical and surgical practice is completely determined by yesterdayscientific research; tomorrow won't be different.

Keywords: Academy. Medicine. Medical management. Medical technology. Bench to bed. 


\section{"I would suggest that the whole imposing edifice of modern medicine, \\ for all its breath-taking success, is, like celebrated tower of Pisa, slightly off balance".}

Charles, Prince of Wales.

$\mathrm{E}_{\mathrm{t}}^{\mathrm{n}}$ este momento, en el que importantes tomas de decisiones que afectan a la asistencia médica han sido negadas a los profesionales sanitarios y cuando la mediocridad intelectual conspira, consciente e inconscientemente, para reducir a los médicos a meros proveedores de unidades asistenciales contables -productos-, se está haciendo cada vez más difícil mantener la calidad -asistencial, docente e investigadora-, y ello supone exponer a los pacientes a un riesgo inexcusable ${ }^{1}$.

\section{CAMBIO EN LA PERCEPCIÓN DE LA PRÁCTICA MÉdICA}

Lewis Thomas ${ }^{2}$ ha sugerido que hubo que esperar hasta la década entre los años 1910 y 1920, para que el encuentro con el médico fuera beneficioso para el paciente. Sólo tras el descubrimiento de las sulfamidas primero y de los antibióticos años después, los tratamientos comenzaron a ser eficaces. Ello aupó a la medicina a los primeros lugares de reconocimiento público; una situación que, paradójicamente, no se mantuvo. La confianza en la profesión médica ha disminuido conforme ha aumentado la capacidad de curar.

Una manera sencilla de documentar este incremento en el poder de la medicina, queda reflejada, por ejemplo, en el cambio en las tasas de mortalidad de los soldados norteamericanos heridos en combate, en las últimas guerras en las que EE UU estuvo implicado ${ }^{3}$. Entre la Primera Guerra Mundial y la de Vietnam, la mortalidad por traumatismo cráneo-encefálico disminuyó desde el 13,9\% al 3\%; en las heridas de tórax, la mortalidad disminuyó desde el $24 \%$ al $7 \%$, y en las heridas de colon, desde el $66,8 \%$ al $6,5 \%$. Antes de la Gran Guerra, una herida de colon era inevitablemente mortal. Probablemente, la mejor manera de ilustrar este fenómeno es referirse a los cambios producidos en la expectativa de vida.
Cuando nacieron mis padres, allá en la primera década del siglo pasado, la esperanza de vida de los ciudadanos de los países desarrollados rondaba los cincuenta años; mis nietos encaran una expectativa de ochenta años: un incremento de treinta años en cuatro generaciones. Los neandertales apenas vivian veinticinco años; tuvieron que pasar 125,000 años para añadir otros 25 años a la expectativa de vida, y sólo un siglo para adicionar treinta años más. Cómo ha sido posible. Por supuesto y en primer lugar, se debe a las medidas higiénico-sanitarias; pero también, señala Lewis Thomas, "a los brillantes avances en nuestra comprensión de los mecanismos básicos de las enfermedades y a la sorprendente adaptación de la tecnología a la medicina" ${ }^{4}$.

Sin embargo, saturado por los logros espectaculares de la ciencia médica, el público comenzó a recibir aterrorizado las noticias de los errores médicos, que comenzaron a ser objetivo favorito de los medios de comunicación. El catalizador fue, probablemente, el tratamiento de la prensa de Nueva York del caso de Libby Zion, un joven paciente cuya muerte en la Unidad de urgencias en un hospital de aquella ciudad, en 1984, fue atribuida, de manera inapropiada por los medios, a la falta de sueño de un residente ${ }^{5}$. En el año 1999, el Instituto de Medicina estudió la prevalencia de los errores médicos, estimando que en EE UU tales errores causaban 98,000 muertes al año ${ }^{6}$. Aun manejando las cifras más benévolas, la tasa de muertes por error médico en los hospitales de EE UU es superior a las debidas a accidentes de tráfico, a cáncer de mama o al sida. Entre los problemas que surgen durante la atención clínica, los más frecuentes tienen lugar en los quirófanos, en las unidades de cuidados intensivos y en las unidades de urgencia. Los errores no sólo tienen un importante coste económico sino que también son gravosos por la pérdida de confianza del público en la medicina, y por la pérdida de satisfacción de los pacientes y de los profesionales sanitarios. ¿Cuántos errores médicos se comenten en nuestros hospitales? Investigar el porqué de los errores es investigación científica médica, y más. Cuando ocurren contratiempos debidos a errores de medicación, por ejemplo en una unidad de cuidados intensivos, los responsables de diseñar el currículo de 
los pregraduados y postgraduados y de los programas de educación continua, deben investigar donde está la raíz del error ${ }^{7}$.

"Estamos, verdaderamente, en medio de una revolución, y todos sabemos que quienes dirigen nuestros programas sanitarios no están ni remotamente interesados en la docencia o en la investigación médicas. En algún momento a mediados de la década de los años 1980, el mundo de los negocios cayó en la cuenta de que lo que hoy llamamos "cuidados de la salud" representaba una industria mil millonaria mal gestionada y lista para ser conquistada. La empresa movió ficha: la capitalización de la impresionante inversión realizada en el pasado por la sociedad en educación e investigación, y la rápida reconversión de los hospitales con un $\mathrm{CEO}$-chief executive officer- al frente" ${ }^{8}$. En Europa, el panorama dista de la situación planteada; el protagonista no es el mundo de los negocios sino el mundo de la política, que comparte la filosofia subyacente. Los organigramas de los hospitales universitarios cuelgan de la figura del "gerente" -persona que lleva la gestión administrativa de una empresa o institución-, a quién los responsables políticos les han encomendado gestionar -llevar a cabo acciones dirigidas a conseguir algo- las listas de espera (solitario y omnipresente indicador de las políticas de salud) y las "peonadas" (epíteto que bien expresa a donde se ha ido a parar). Ante ello, la pregunta es si la Academia -la calidad asistencial, docente e investigadora- tiene cabida, hoy, en los centros asistenciales llamados académicos o universitarios ${ }^{9}$; porque la medicina académica se define como la capacidad del sistema de salud y de la atención clínica de pensar, estudiar, investigar, descubrir, evaluar, innovar, enseñar, aprender y mejorar.

Sin embargo, todos, los políticos y los diferentes profesionales del Sistema de Salud, deberian tener bien presente que la atención sanitaria o médica o clínica del mañana, depende de la formación y de la investigación de hoy. Vale la pena recordar, por ejemplo, a Pierre Mendès-France: "La República necesita científicos; sus descubrimientos, el prestigio que conllevan y sus aplicaciones forman, todo ello, parte de la grandeza del país". Convicciones similares han sido expresadas por otros estadistas ${ }^{10}$; por el contrario, nues- tro parlamentarismo es parco en el tema. ¿Confiarian nuestros políticos la responsabilidad del mando del buque insignia de nuestra flota a un "gerente»? ${ }^{11}$. Una cosa es la utilización inteligente de los recursos y otra el huero economicismo. Pero también juega en contra la despreocupación de nuestra sociedad civil por la ciencia ${ }^{12}$.

Los centros médicos académicos o universitarios -al menos así consta en las fachadas de nuestros hospitales- tienen la responsabilidad de proporcionar una atención sanitaria ejemplar a los enfermos, enseñar medicina a los estudiantes, formar a los futuros profesionales y aportar nuevo conocimiento a través de la investigación. En vez de ello, los centros se convierten en dispensarios y en solucionadores de problemas más sociales que médicos. Hay que reinventar el sistema, porque ni reformas ni reestructuras son suficientes: existe la tendencia de que cuando se topa con problemas complejos, se opta por soluciones simples. Henry Mencken ${ }^{13}$ dijo que "para cada problema complejo existe una solución simple y errónea". No hay una solución simple; son tantos los factores involucrados que es imposible predecir un futuro que está por venir desde el desencanto.

Richard Anderson ${ }^{14}$ caracterizó los desarrollos médicos históricamente recientes en décadas: la de los años 1960, década la innovación clínica; la de 1970, década de la expansión clínica, y la de los ochenta, década de la restricción financiera. Para la década de los años 1990, Alexander Walt ${ }^{15}$ acuñó el término "dis-decade». Un término que resume una enmienda a la totalidad: "Medical education: a continuum in dis array + dis affected public (lack of humanism) + dis spirited residents (service versus education) + $\underline{\text { dis }}$ functional government (declining financial resources) + $\underline{\text { dis }}$ organized speciality movement (fragmentation) $+\underline{\text { dis }}$ couraged faculty (relative value of surgical education) $=$ decade of dis enchantmentw.

\section{EL LABORATORIO, LA CLÍNICA Y LA COLABORACIÓN}

Antes de la Segunda Guerra Mundial, la investigación biomédica en general y la quirúrgica en particular se financiaban por fondos institucionales y privados y prácticamente nada por ayudas del gobierno; ello en EE UU, lo que signi- 
fica en el resto del mundo desarrollado. En el año 1949, Vannevar Bush, Director de la Oficina de Investigación Científica y Desarrollo, consiguió que el gobierno, a través de los NIH (National Institutes of Health, Bethesda, USA), participara sustancialmente en la financiación científica. La doctrina Bush, definida en 1945 y que en gran parte condicionó el futuro de los NIH, fue potenciar la investigación básica sobre la clínica: «E1 progreso en el tratamiento de las enfermedades será el resultado de descubrimientos fundamentales en temas no relacionados con la enfermedad" ${ }^{16}$. El entusiasmo por la investigación básica fue consolidado por la publicación de la estructura del ADN por James Watson y Francis Crick ${ }^{17}$ en 1953 y que supuso el comienzo de la era de la biología molecular.

Seguidor de la doctrina Bush, James Shannon ${ }^{18}$, que dirigió los NIH durante las décadas de los años 1950 y 1960, convenció a los líderes políticos de que la mejor estrategia para curar las enfermedades era desbrozar las bases moleculares subyacentes de la fisiopatología. Shannon razonó que, como los investigadores de la era premolecular, los biólogos moleculares, tras elucidar los mecanismos básicos de la enfermedad en sus laboratorios, retornarian con sus descubrimientos a la cabecera del paciente donde los traducirían en nuevos y eficaces tratamientos. La investigación clínica en general y la quirúrgica en particular estaban muy lejos del interés científico de los NIH que, siguiendo la doctrina BushShannon, se decantó por lo básico. La investigación realizada por los cirujanos estaba dirigida a resolver problemas específicos encontrados durante la asistencia a los pacientes, y aunque se movian en un nivel supramolecular, la mayoría de las ocasiones sin ayuda federal alguna, hicieron contribuciones muy importantes a la solución de complejos problemas asistenciales.

En su discurso presidencial ante el American College of Surgeons (ACS), en el año 1999, James Thompson ${ }^{8}$ se refirió a las contribuciones quirúrgicas más importantes de los últimos cincuenta años de la era molecular: cirugía cardiaca, cirugía vascular, efecto de las hormonas sobre el cáncer, respuesta metabólica al trauma, quemaduras y sepsis, ensayos clínicos de quimioterapia y cirugía conservadora en el cáncer de mama, nutrición parenteral total, órganos artificiales y trasplante de órganos; lo que podría ampliarse con el reemplazamiento completo articular, la cirugía fetal o la neurocirugía estereotáxica. Por su parte, John Bell, Regius Professor de Medicina en Oxford y biólogo molecular, refiriéndose a los descubrimientos en genética molecular con mayor potencial de aplicación clínica durante aquellos mismos años, reconoció que la biología molecular, hasta el momento, no había tenido en la clínica el impacto esperado. La genética y la medicina molecular no serán, por supuesto, la respuesta a todas las preguntas sobre la salud humana ni, menos aún, la llave optimizadora de la práctica clínica. El reduccionismo que acompaña a la genética molecular identificará las piezas de esos problemas, pero su ensamblaje para comprender el mal funcionamiento de esos complejos sistemas exige una estrategia mucho más integrada de la que hoy predomina ${ }^{19}$. Por ello, aunque la ciencia básica de los primeros cincuenta años de la era biomolecular es fascinante y su porvenir inmenso, no debe sorprender que muy pocos pacientes se hayan beneficiado de ella.

La paradoja de la poca repercusión clínica de la investigación molecular podía explicarse a partir del punto flaco de la doctrina Bush: el apoyo gubernamental a la investigación se ocupó, exclusivamente, de la ciencia básica. En 1979, James Wyngaarden, director de los NIH, detectó una despreocupación de los médicos interesados en la investigación científica por los problemas clínicos; señaló que los médicos interesados por la investigación clínica eran una especie en peligro de extinción ${ }^{20}$ : "Las razones por las que el interés de los jóvenes médicos ha disminuido son complejas. Una importante es la reevaluación de los objetivos de la sociedad tras el conflicto de Vietnam. Un replanteamiento de intereses que ha conducido a poner más énfasis en la atención médica de los segmentos desprotegidos de nuestra sociedad que en la investigación biomédica básica, a efectos de mejorar la salud y conquistar la enfermedad [...] Existe cierto sentimiento entre los estudiantes de medicina de que la tecnologia de la medicina ha sobrepasado su sociología [... Un segundo factor importante es la inestabilidad del apoyo gubernamental a la investigación bio- 
médica [...] Un tercer factor es la revisión del currículo [... cuyo] resultado es que muchos profesionales alcanzan el final del periodo de residencia sin conocimiento alguno de primera mano del trabajo en el laboratorio... Otra influencia importante [... es que] un porcentaje significativo de médicos jóvenes, que en el pasado habrían pospuesto la economia por la curiosidad de investigar, son ahora víctimas del que se ha denominado "resident-fellow-Porsche-syndrome" [...] Existen reservas abundantes de conocimiento científico en biología y en medicina, y las oportunidades de su aplicación a problemas médicos no solucionados nunca han sido tan evidentes. El progreso está en marcha y el momento no debe perderse».

Al ensayo de Wyngaarden siguieron otros similares. Gordon Gill escribía, en 1984, que "el primer factor para el cambio [producido] fue práctico y económico [...] los hospitales académicos comenzaron a contratar más clínicos y menos investigadores [...] El segundo factor fue quizás más profundo. La naturaleza de la biología molecular y de la verdadera ciencia básica cambió con el desarrollo de la tecnología del ADN recombinante; el cambio fue tan rápido que, sin tiempo para reaccionar, la revolución puenteó el mundo médico [...] El papel de los departamentos académicos de medicina y el de los médicos cambió. Su papel, ahora, es aplicar los avances conseguidos [en los laboratorios], comprobar su eficacia y seguridad en la clínica [...] los biólogos moleculares dominan, ahora, toda la ciencia biológica [...] Numerosos clínicos interesados en investigación han sido seducidos por el poder de la biología molecular y han abandonado la investigación clínica. Estos médicos prefieren presentar sus trabajos en las reuniones en Cold Spring Harbor, el no va más para los científicos básicos, que en el Sheraton de Washington DC, que acoge anualmente la reunión ASCI/AAP/AFMR ${ }^{21}$. La contribución de un tercer factor, en comparación con los anteriores es más dificil de precisar [...] Una marea de anti-intelectualismo se extiende a través de los países Occidentales [...] Los estudiantes de medicina comienzan a acudir durante los veranos a las zonas más deprimidas, no a los laboratorios" ${ }^{22}$. A pesar de todo, hubo voces optimistas; para Robert Glickman la investigación clínica "ni está muerta, ni la dejaremos morir»"23.
«En mi alocución presidencial me apartaré del tradicional discurso filosófico. En vez de ello aprovecharé esta ocasión -escribe Joseph Goldstein en relación con su discurso ante la LXXVIII Reunión anual de la Sociedad Americana para la Investigación Clínica ${ }^{24}$ - para describir un síndrome clínico recientemente identificado. Esta enfermedad devastadora aflige a nuestros más brillantes y más prometedores clínicos-científicos; una enfermedad que les invalida en el momento justo de su maduración como investigadores. El sindrome se denomina PAIDS (Paralyzed Academic Investigator's Disease Sindrome)". El PAIDS consiste en la incapacidad de un investigador para capitalizar una observación original. La fisiopatología la define Goldstein en cuatro palabras: carencia de entrenamiento apropiado. También se atreve a prescribir el tratamiento: sólido entrenamiento en ciencia básica y coraje técnico. Lo primero es obvio. Coraje técnico es la autoconfianza y el sentido de aventura que emergen de lo primero; es el coraje para utilizar nuevas técnicas para contestar nuevas preguntas; es el coraje de evitar la fosilización en lo que uno ya conoce.

El pretendido modelo de Shannon del médicocientífico que trasladara sus descubrimientos en investigación molecular a la cama del enfermo, no funcionó. En vez de ello, el investigador básico se encerró en el laboratorio. La predicción de que la financiación de los NIH potenciaría la ciencia fue un éxito -por ejemplo la identificación de oncogenes y de genes supresores de tumores-, pero la idea de Shannon de que el mismo científico que hacía tales descubrimientos los aplicara en la clínica, fracasó. Además, como la ciencia básica progresaba y se hacía más y más interesante, los médicos que se habían acercado a ella se fueron afincando en proyectos de laboratorio y abandonaron la clínica.

El artículo de Goldstein antes citado parece escrito desde la nostalgia "shannonista". Poco más de diez años después, esta vez en coautoría con Michael Brown, retomaba el tema aunque con un punto de vista diferente ${ }^{25}$. En 1986, Goldstein ilustró el coraje técnico refiriéndose a tres ilustres médicos -tres gigantes de la investigación biomédica- que lo habían practicado: Archibald Garrod, el padre de la genética bioquí- 
mica; Karl Landsteiner, el padre de la inmunoquímica, y Rudolph Schoenheimer, el padre de la bioquímica molecular. Los tres habían compaginado clínica y laboratorio.

Ahora, Goldstein y Brown (JG y MB, de la University of Texas Health Science Center, en Dallas, fueron galardonados con el Premio Nobel de Fisiología o Medicina 1985, por sus descubrimientos relacionados con la regulación del metabolismo del colesterol) indicaron que el médico interesado en investigación, una vez que ha completado su entrenamiento clínico, puede plantearse tres tipos de estudios: investigación básica, investigación orientada a la enfermedad (DOR: disease-oriented research) o investigación orientada al paciente (POR: patient-oriented research). Las dos primeras opciones están abiertas tanto a biólogos como a médicos; la tercera queda restringida a los segundos. La distinción entre DOR y POR es importante porque mientras que la investigación básica y DOR prosperan, POR languidece. DOR es aquella investigación dirigida hacia la comprensión de la fisiopatología o del tratamiento de la enfermedad, pero no requiere del contacto directo entre paciente y científico. Puede utilizar materiales procedentes de pacientes, pero no al paciente como persona. POR esta realizada por médicos clínicos quienes observan, analizan y tratan a personas enfermas. Como regla de oro, si el investigador estrecha las manos del paciente durante el transcurso de la investigación, está realizando POR; y ese contacto directo exige anteponer la dignidad del paciente por encima de cualquier otra consideración ${ }^{26}$.

Muchos eminentes científicos, incluidos los Premios Nobel Arthur Kornberg (en 1959, ADN polimerasa), François Jacob (en 1965, operón lac) y Daniel Nathans (en 1978, enzimas de restricción) fueron médicos entrenados en clínica -realizaron internados y residencias en medicina o cirugía- y que, después, se dedicaron por completo a la investigación básica. Landsteiner, Schoenheimer y Oswald Avery practicaron DOR. Avery, un clínico estimulado por los pacientes con neumonía neumocócica, estudió el mecanismo por el que cepas avirulentas de neumococos se transformaban en otras virulentas; el resultado fue el descubrimiento de que los genes están constituidos por ADN. Un caso análogo es el de los ya citados Goldstein y Brown, quienes espoleados por el caso de una niña de seis años con hipercolesterolemia familiar homocigótica acabaron enfrascados en los mecanismos de control del metabolismo del colesterol mediados por receptores. Por su parte, el padre de la POR fue Garrod; a partir de sus observaciones en pacientes con alcaptonuria y en colaboración con William Bateson, un científico básico dedicado a genética, sugirió que los errores metabólicos congénitos están causados por defectos genéticos que afectan a las enzimas que catalizan pasos metabólicos claves en una ruta bioquímica determinada. Su conclusión, en 1908, de que los genes codifican enzimas se adelantó en 35 años al redescubrimiento del mismo fenómeno en Neurospora por George Beadle y Edgard Tatum, lo que les valió el Premio Nobel 1958. POR del tipo realizado por Garrod tiene numerosos ejemplos contemporáneos: Allen Steere y Steve Malawisa (enfermedad de Lyme), Michael Gottlieb (sida), William Waddell y Richard Loughry (inhibidores de la cilooxigenasa previenen el cáncer de colon) o Barry Marshall (Helicobacter pylori causa úlcera gastroduodenal). Los individuos señalados y otros que realizaron POR con éxito, comparten, generalmente cuatro Ps: pacientes, paciencia, pasión y pobreza (en ayudas a la investigación). Por trasladar conocimiento a la cabecera del paciente, este tipo de investigador clínico también ha sido denominado POCTIs (patient-oriented translational clinical investigators) ${ }^{27}$.

Goldstein y Brown dieron una explicación para la seducción de la investigación básica: «Es fácil tener éxito en la investigación básica que, además, es más sencilla de realizar que la investigación clínica. El científico básico puede elegir un problema listo para solucionar porque hay a mano nuevas herramientas o porque otro investigador ha hecho un descubrimiento que despeja un atolladero experimental [...] siendo relativamente fácil anticipar el nuevo experimento y realizarlo. Este tipo de investigación básica, aunque no es revolucionaria, produce sin embargo resultados definitivos [...] que pueden ser publicados en revistas respetadas que cualificarán al investigador para obtener ayudas [...] La ciencia básica procede mediante la abstracción [...] Las com- 
plejidades de los órganos integrados y de los sistemas orgánicos [...] son excluidas deliberadamente [...] Por el contrario, el mundo complejo de las enfermedades es el foco obligado del científico clínico. Los investigadores clínicos no tienen la libertad de elegir sus objetivos. Deben jugar con lo que la naturaleza les brinda. El reumatólogo trabaja con la artritis reumatoide no por mero interés sino porque el paciente la padece [...] Rara vez el clínico soluciona el problema con la brillantez con que el básico lo consigue».

Alvan Feinstein ${ }^{28}$ y Gordon Williams ${ }^{29}$ creen que Shannon fue un incauto al presumir que tras el entrenamiento que posibilitaría a los médicos científicos hacer descubrimientos básicos, esos mismos médicos aplicarian sus hallazgos para resolver los problemas de sus pacientes. Aunque fueran médicos, habían sido entrenados en la "escuela reduccionista". La estrategia reduccionista aborda células y moléculas y no es una buena aproximación a los problemas fisiopatológicos, que no son del interés de los reduccionistas. Los procesos complejos que tienen lugar en los organismos vivos solo pueden comprenderse a través de una aproximación integradora. Las enfermedades humanas ocurren en organismos y en sistemas, no en moléculas que no enferman. Los reduccionistas no se interesan por procesos groseros como bloqueo, espasmo, isquemia o descompensación; enfrascados en problemas básicos rara vez se acercan a la clínica para contestar problemas relacionados con el paciente.

Wyngaarden, Feinstein, Williams, Goldstein y Brown, $y$ otros $^{30}$ han expresado su preocupación por el peligro de extinción de los médicos científicos ocupados con los problemas clínicos, reclamando para su rescate un entrenamiento especial y el apoyo a la investigación clínica y traslacional. El modelo que todos ellos proponen es que la investigación básica continúe siendo realizada por científicos básicos, procedan de la medicina, de la biología, de la química o de la física, pero a tiempo completo. Los hallazgos que de ello resulten deberán ser recogidos por otros investigadores, diferentes; investigadores clínicos especializados que hagan el traslado. Se va extendiendo el consenso de que un individuo no debe actuar, simultáneamente, como investigador básico y clínico; ningún individuo tiene que conocer "todo" 31 .
Una ruta para la salvación de la POR es la colaboración. Una colaboración que no es aquella a gran escala -macro-redes-; es una más simple: entre dos individuos que aseguren la fertilización cruzada $^{32}$ o el mestizaje entre campos dispares. Una intima y estrecha colaboración que les permiten, juntos, cubrir una panorámica que, individualmente, les estaría vedada. Los dos colaboradores deben tener un entrenamiento en medicina y en ciencia, que les permitirá estar en ambos lados a la vez, aunque uno en la clínica y el otro en el laboratorio; incluso pueden cambiar los papeles periódicamente. Es el tipo de colaboración practicado por Brown y Goldstein. Puede que más "normal" e incluso más potente sea la colaboración entre pares, que juegan cada uno de ellos un papel permanente: un clínico y un científico. Este tipo de colaboración ha dado frutos importantes; fue el caso citado de Garrod y Bateson. Sirvan dos ejemplos: los corticoides y la fertilización in vitro (FIV).

La historia de la cortisona se inicia en la década de los años 1930 e implica a dos pioneros: un clínico, Philip Hench, y un químico, Edward Kendall. En 1929 Hench, un reumatólogo en la Clínica Mayo, observó que varios de sus pacientes con artritis reumatoide avanzada experimentaban una notable mejoria en dos circunstancias: embarazo e ictericia. Hench pensó que esas dos situaciones inducian la producción de un factor anti-inflamatorio, que denominó "sustancia $\mathrm{X}$ anti-reumática", y concluyó, tras varios ensayos terapéuticos frustrados, que el denominador común en el embarazo y en la ictericia era una concentración incrementada de colesterol en la sangre y que, dada la riqueza en colesterol de la glándula adrenal, esta debería ser la fuente de la pretendida sustancia X. A mediados de la década de 1930, Hench inició la colaboración con Kendall, un químico de la misma institución, quién había aislado la tiroxina de la glándula tiroides y que, entonces, se ocupaba de aislar sustancias adrenales que mantuvieran con vida perros adrenalectomizados. En 1934 había conseguido aislar 28 compuestos, de los que seis mostraban actividad en bioensayos y a los que denominó compuestos A-F. Su caracterización supuso diez años de trabajo y manejar 150 toneladas de glándulas adrenales bovinas. El primer 
esteroide purificado, el compuesto A (11-deshidrocorticosterona), fue ineficaz en los ensayos clínicos de Hench. En 1946, Kendall aisló el compuesto E (cortisona), que resultó ser la sustancia $\mathrm{X}$ anti-inflamatoria en ensayos en perros. Kendall fue incapaz de sintetizar la cantidad suficiente del producto para poder ser administrado a pacientes. El problema se resolvió tras llegar a un acuerdo de colaboración con Merck \& Co Inc, cuyos químicos, bajo la dirección de Lewis Sarret, diseñaron un proceso de sintesis química de la cortisona que constaba de 37 reacciones químicas encadenadas; la sintesis química más compleja llevada a cabo por compañia farmacéutica alguna. En 1948, los científicos de la Merck fueron capaces de producir varios gramos de cortisona; cantidad suficiente para tratar a un paciente reumatoide con $100 \mathrm{mg}$ /i. $\mathrm{m} / 24 \mathrm{~h}$, durante nueve días. El éxito del tratamiento fue incuestionable. Hench y Kendall presentaron su trabajo en la reunión anual de la AAP, en 1949. Tras la presentación, Walter Bauer, Jefe de Medicina del Hospital General de Massachussets y uno de los clínicos más respetados del mundo, remarcó no haber presenciado tratamiento tan efectivo alguno en toda su vida profesional. La cortisona no habría visto la luz sin la colaboración de un clínico, de un científico y de un tercer ingrediente que, cada vez, reclama mayor protagonismo: una compañia farmacéutica. Un buen ejemplo de cómo ganar los máximos retornos a los esfuerzos científicos ${ }^{33}$.

El segundo ejemplo elegido de la eficacia de la colaboración es la que permitió aplicar en la clínica la fertilización in vitro. En 1937, John Rock anticipó la posibilidad de la FIV ${ }^{34}$. El artículo inspiró a Gregory Pinkus, luego internacionalmente famoso por su papel en el desarrollo de la píldora anticonceptiva, a realizar FIV con conejos, a la vez que Rock y Miriam Menkin consiguieron, en 1944, que un oocito humano se dividiera en dos células. El renacimiento de la FIV como tratamiento de la infertilidad tuvo lugar en la década de los años 1960, de la mano del fisiólogo Robert Edwards, a quién la ginecóloga Molly Rose le proporcionaba tejido ovárico de pacientes sometidas a laparotomía. Solucionados los problemas planteados con la regulación hormonal, Edwards fue consciente de que si la FIV podría llegar a ser una realidad clínica, era necesario disponer de un método alternativo de obtener óvulos. La contestación fue la laparoscopia, que había sido introducida en Inglaterra por Patrick Steptoe, a la par que Edwards conseguía los primeros éxitos con la fertilización de óvulos humanos in vitro, y que, en abril de 1968, se desplazaba al hospital donde trabajaba Steptoe, con todo su equipamiento. En 1971, los recursos se centralizaron en Cambridge. En noviembre de 1973, Edwards publicaba sus primeros ocho intentos de FIV humana, sin éxito. En julio de 1978 nacía Louise Joy Brown, la primera bebé probeta.

No debe suspirarse por el tradicional médico cientifico. Judith Swain ${ }^{35}$ escribe: "Los médicos que compiten con los investigadores básicos deben compartir su tiempo en investigación, educación y clínica, y destacar en las tres. Por otro lado, la medicina clínica no es una actividad que pueda desempeñarse a tiempo parcial». Una opinión similar la plantea Ronald Arky ${ }^{36}$ : "A final de la década de los años 1940 y principios de los 1950, el jugador trivalente de rugby comenzó a difuminarse; los jugadores que podian correr, pasar y patear y puntuar fueron siendo reemplazados por especialistas en cada una de esas habilidades. De manera similar, en medicina hubo, en un tiempo pasado, médicos trivalentes: investigadores, docentes y clínicos. Me sorprendería que, hoy, hubiera unos pocos, si es que hay alguno, de tales médicos trivalentes". Una reflexión similar fue expuesta hace diez años por Robert Conter ${ }^{37}$, $\mathrm{y}$ hace ya veinte años por Bernardine Healy ${ }^{38}$.

En cirugía, la trampa reduccionista, que hace a la investigación ocuparse de las moléculas y no de las enfermedades o de los pacientes, no tuvo gran incidencia. Primero, porque el cirujano siempre piensa como fisiopatólogo: bloqueo, espasmo, isquemia; y segundo y desafortunadamente porque los cirujanos rara vez tienen tiempo de llegar a ser expertos en biología molecu$\operatorname{lar}^{39}$. Wiley Souba ${ }^{40}$, en "reinventar para el futuro", comenta que "las iniciativas de investigación estarán organizadas programáticamente [...] Si la investigación biomédica "pedestre" sobrevive, será a una escala mínima".

\section{INVESTIGACIÓN QUIRÚRGICA}

Los cirujanos son acusados con frecuencia de la poca atención que prestan a los aspectos 
académicos de la profesión, particularmente a la investigación. Edgard Churchill -figura señera de la cirugía de Harvard- señaló, en 1947, que si los cirujanos dejaran de crear nuevo conocimiento propio y de desarrollar nuevos tratamientos a través de la investigación, se convertirian en meros técnicos a las órdenes de los colegas internistas ${ }^{41}$. La cirugía es más que destreza.

$\mathrm{Si}$, a pesar de todo, el cirujano intenta acercarse a la investigación, debe sortear una serie de dificultades: los científicos básicos, que creen que el bagaje científico de los cirujanos y su tiempo disponible son insuficientes para abordar un proyecto de investigación con seriedad; los internistas académicos, que piensan como los científicos básicos; los comités científicos, repletos de básicos y de internistas; las agencias de financiación, que exigen un tiempo de participación imposible de retraer a su dedicación quirúrgica, y los métodos de selección, que dejan en franca desventaja el trabajo publicado en una revista quirúrgica frente a otro publicado en Cell, Nature o Science. También y como menciona Judah Folkman ${ }^{42}$, un elemento disuasorio para el éxito científico, tan importante o más que los anteriores, es la personalidad del cirujano. El modelo prototípico del cirujano exhibe, generalmente, las siguientes características: decisión, confianza y la capacidad de actuar con prontitud, si es necesario, antes de tener en la mano la totalidad de los datos. Todo ello es necesario en la sala de urgencia o en el quirófano, pero no es la mejor fórmula para realizar ciencia. Con todo, los cirujanos se adelantaron a la investigación traslacional, como muestran unos pocos ejemplos. Cirugía cardiaca. Alfred Blalock y su ayudante Vivien Thomas intentaron desarrollar un modelo de hipertensión pulmonar en el perro; para ello anastomosaron la arteria subclavia a la arteria pulmonar. Fue un fracaso; la circulación pulmonar se acomodaba rápidamente al incremento súbito de flujo de sangre sin incrementar la presión. Años después, tuvo la oportunidad de convertir el fracaso experimental en un triunfo clínico. Cuando la cardióloga pediatra Helen Taussig sugirió que un incremento del flujo en la arteria pulmonar podría beneficiar a los "niños azules" con tetralogía de Fallot, Blalock rescató su modelo experimental con pleno éxito. La primera operación la realizó el
29 de noviembre de $1944^{43}$. El desarrollo de una máquina corazón-pulmón o de circulación extracorpórea por John Gibbon será tratado al final de este capítulo.

Cirugia vascular. Las primeras anastomosis vasculares fueron realizadas, hace poco más de cien años, por Mathieu Jaboulay y su estudiante Alexis Carrel, a quién se atribuyen las innovaciones más importantes en cirugía vascular, incluidas algunas que fueron aportadas por otros. El éxito de Carrel se debe a que, efectivamente, introdujo un método de sutura vascular completamente nuevo y a la meticulosidad de su técnica que evitaba hemorragias y trombosis post-quirúrgicas del vaso. A causa de su fracaso en las pruebas de acceso para ocupar una plaza de cirujano en su país, emigró primero a Canadá y, al año siguiente, a EE UU. Por su trabajo recibió el Premio Nobel de Fisiología o Medicina $1912^{44}$. Todo el trabajo de Carrel, que fue realizado en animales, cayó en el olvido durante cuarenta años, hasta que se inició la cirugía vascular en humanos. Las primeras reparaciones de aneurismas de la aorta se realizaron a comienzos de la década de los años 1950. Al principio, los defectos de la arteria eran reparados con homoinjertos frescos o conservados que, generalmente, degeneraban con resultados, en ocasiones, desastrosos. La cirugía de los grandes vasos tuvo que esperar al desarrollo de prótesis artificiales; un desarrollo fruto de una observación accidental, en 1952, por Arthur Vorhees. La autopsia de un paciente a quién se había practicado una intervención cardiaca meses antes, mostró que una sutura mal colocada atravesaba la cavidad ventricular. La sutura, recubierta de endotelio, semejaba una cuerda tendinosa valvular normal. Vorhees pensó que si el endotelio había recubierto la sutura, lo mismo haría con una prótesis artificial. De la idea a la práctica. Voorhees y Arthur Blakemore construyeron prótesis que injertaron con éxito en pacientes ${ }^{45}$.

Cirugía endovascular. Hasta comienzos de la década de los años 1990, los cirujanos vasculares veían con complacencia que los radiólogos intervencionistas realizaran procedimientos basados en cateterismo endovascular, tales como dilatación mediante balón de arterias estenóticas y la introducción de stents para prevenir la reestenosis. En 
1990, cuando Juan Parodi ${ }^{46}$ introdujo el tratamiento con prótesis endoarterial transfemoral para tratar aneurismas de la aorta abdominal, los cirujanos vasculares se dieron cuenta de que, a menos que aprendieran las habilidades necesarias para realizar esos procedimientos, se arriesgaban a perder un segmento significativo de su práctica profesional en favor de los radiólogos. Esta corta historia sirve de introducción a dos "distorsiones": el distintivo de la técnica y el papel de la oferta instrumental.

$¿$ Radiología intervencionista, cardiología (o neurología...) invasiva o cirugía sin huellas? Los correspondientes "especialistas" utilizan idénticos medios y técnicas, pero se ubican en diferentes plantas del hospital; con ello incrementan el gasto -el despilfarro no es inversión- y disminuyen su experiencia -a pesar del meta-análisis, que se convierte en una alquimia-. En todo ello no hay más que el conflicto de intereses comentado en el párrafo anterior. La reinvención -no la reforma- del currículo de la Licenciatura, primero, y de los programas de formación de especialistas después, ha de ser la herramienta racionalizadora.

Los modernos cirujanos vasculares han adquirido la destreza suficiente para colocar stents y realizar otros procedimientos endovasculares. Y, con ello, no debe sorprender que el entusiasmo del público para sustituir las grandes intervenciones vasculares por otras menos agresivas, haya sido similar al de la recepción de la colecistectomía laparoscópica. Y como con esta última técnica, este entusiasmo hace imposible los estudios aleatorizados. Sin embargo, la transición a las intervenciones endovasculares no ha sido tan abrupta como en el caso de la cirugía laparoscópica. Una de las razones es la promiscuidad de dispositivos. Los cirujanos colaboran con numerosas compañias fabricantes en una multitud indiscriminada de ensayos clínicos, que se afanan por demostrar las ventajas de cada una de ellos. Cada dispositivo debe conseguir la aprobación de la FDA -Food and Drug Administration. La aprobación o rechazo por esta Agencia significa su aceptación o no, en términos generales, a nivel global- antes de que pueda ser utilizado fuera de un ensayo clínico, y sólo media docena lo han conseguido. El proceso de aprobación es oneroso, pero tiene el mérito de exigir el seguimiento de los resultados de salud; un requisito que no se aplica a otros procedimientos como la cirugía laparoscópica. Por otro lado, a pesar de la disminución de la morbilidad intra y post-operatoria inmediata de las técnicas endovasculares, existen importantes desventajas. Una experiencia de cinco décadas demostrando la eficacia de los procedimientos vasculares estándar o técnicas abiertas es dificil de desbancar. Los diferentes dispositivos endovasculares o técnicas cerradas aunque guiadas por la imagen, difieren en características importantes como el mecanismo de anclaje o la estructura; ello hace que tengan perfiles hemodinámicas y biológicos diferentes. Sólo la vigilancia y seguimiento a largo plazo confirmará que los endo-dispositivos exhiben una durabilidad, en condiciones de normalidad biológica, similar a la de los procedimientos ya consolidados. Esta vigilancia a largo plazo es incómoda para el paciente y para el cirujano. Sin embargo, no cabe duda que los procedimientos endovasculares han revolucionado la cirugía vascular y son un ejemplo de investigación clínica moderna por los cirujanos.

Otro caso de presión comercial lo representa una campaña publicitaria que inundó las marquesinas de las paradas de los autobuses y las estaciones del metro de nuestras ciudades. Una multinacional experta en electromedicina aconsejaba a los usuarios del transporte público, realizarse las exploraciones de imagen con el novísimo "tricorder médico" de la casa. Cómo negarse los hospitales y clínicas a adquirir tal herramienta, demandada por un usuario que exige lo mejor; sobre todo, si los medios de comunicación certifican, a diario, la eficacia del aparato para resolver los más intrincados problemas de los ídolos mediáticos. La evaluación de las tecnologías es investigación ${ }^{47}$.

Cirugía mínimamente invasiva. Probablemente, la técnica que ha cambiado la vida a los cirujanos, más que cualquier otra. En septiembre de 1985, Eric Muhe, en Boblingen, Alemania, realizó con éxito la primera colecistectomía laparoscópica ${ }^{48}$. Dos años después, Phillipe Mouret, en Lyon, mejoró de manera importante la técnica. La cirugía laparoscópica fue popularizada en los hospitales comunitarios y no en los centros académicos, 
donde los cirujanos fueron, al principio, reacios a la nueva técnica. La aceptación generalizada se debió a la demanda de los pacientes basada en la percepción de un menor dolor postoperatorio, menos dias de estancia hospitalaria y periodos más cortos de incapacidad laboral postoperatoria. Aunque esta percepción fue posteriormente sustentada por varios estudios, la influencia de los medios de comunicación y la preferencia de los pacientes y el entusiasmo del cirujano para utilizar las técnicas más novedosas -también distorsiones-, pueden hipotecar los estudios aleatorizados que permitan comparar los resultados de los procedimientos abiertos frente a los minimamente invasivos. Ello, sin que exista argumento alguno para poner en duda que la cirugía minimamente invasiva es una de las principales contribuciones de la investigación quirúrgica clínica de las últimas décadas.

Quirobótica y cibercirugia ${ }^{49}$. Por su parte, el avance imparable de la cirugía apuntada va parejo con el de otras tecnologías ya al alcance de la mano. Cibercirugía es un término que abarca y describe un nuevo concepto de la cirugía. Una nueva palabra con la que el cirujano puede entender y reimaginar su oficio en la era de la información. Integra, en el ámbito de la cirugía, tanto una complementariedad emergente entre clínicos y máquinas -especialmente computadoras-, como diversas tecnologías digitales. Por otro lado, la cibercirugía simboliza una nueva y verdadera opción revolucionaria. Hace suyos el paradigma de la información en el que los bits reemplazan a los átomos y moléculas, la visualización tridimensional aportada por las nuevas tecnologias de imagen médica y la realidad virtual a partir de tecnologias integradas. Nuevas tecnologías a las que los jóvenes cirujanos -cirujanos nintendo ${ }^{50}$ - llegan mejor preparados sobre la base de que sus capacidades hápticas han sido potenciadas, durante su juventud, por los videojuegos. La cibercirugía es la sintesis completa de todos esos componentes, que ya están, casi, aquí: quirobótica -"quiro" + (ro)bótica-, inteligencia artificial, computación de alto rendimiento, telepresencia o Internet. Como en las revoluciones previas -asepsia, anestesia, etc.-, el resultado de la integración será muy superior a la suma de las partes.
Nutrición parenteral total. En 1938, Isador Ravdin y Jonathan Rhoads estudiaban la repercusión desfavorable de la malnutrición proteica sobre la evolución de la cicatrización de las heridas. Durante los siguientes 25 años persiguieron el objetivo de conseguir un balance nitrogenado positivo en pacientes incapaces de comer; para ello siguieron diferentes estrategias, como infusiones rectales de glucosa y alcohol o administración endovenosa de gelatina y grasas. Retirado Ravdin, Rhoads persistió en la investigación ayudado de una larga serie de ayudantes. Stan Dudrick, un residente que trabaja en el laboratorio de Rhoads, llevó a cabo el experimento decisivo. Francis Moore, el principal competidor en esa línea de trabajo, describió, años después, el experimento: "Finalmente su equipo [...] incluyendo al Dr. Wilmore, al Dr. Vars y al Dr. Dudrick realizaron ese simple experimento en cachorros de perro que proporcionó al mundo la moderna nutrición endovenosa y ese galimatías de términos - alimentación parenteral total. Fue un experimento que no necesitó estadísticas. No fue complejo. Fueron simples y directos, derechos al problema y muy, muy contundentes. No necesitaron grandes números. Se limitaron a demostrar que los cachorros crecían normalmente alimentándose, exclusivamente, por vía endovenosa ${ }^{51}$. La suerte contribuyó en parte al éxito. Uno de los colaboradores, Harry Vars, era un excelente bioquímico-reparó las soluciones alimenticias endovenosas- y un gran inventor; ideó un arnés que permitió la infusión endovenosa continua durante meses; y, en segundo lugar, apareció por el hospital un residente de urología de otro centro, en periodo de rotación, que conocía una técnica para la cateterización percutánea de la vena subclavia, y que enseñó el procedimiento a Dudrick. Ello proporcionó la clave para mantener una infusión continua endovenosa de una solución hiperosmolar, sin riesgo de trombosis.

Trasplante. En la primera década del siglo xx, Alexis Carrel demostró la viabilidad técnica del trasplante de órganos. Tras la Segunda Guerra Mundial, Francis Moore, jefe de cirugía del Hospital Peter Brigham, de la Universidad de Harvard, animó a su residente, David Hume, a intentar trasplantar riñones en pacientes con fracaso renal terminal y a pesar del persistente fra- 
caso en perros. En 1947, un equipo integrado por Charles Hufnagel, cirujano del hospital, Ernest Landsteiner, jefe de residentes de urología y por Hume, trasplantó el riñón procedente de un cadáver en la fosa antecubital de una paciente en fracaso renal agudo secundario a un aborto séptico: anastomosaron los vasos renales a la arteria y vena braquiales; el uréter drenaba directamente en un reservorio. El riñón funcionó durante 48 horas, siendo retirado al tercer día; la enferma se recuperó ${ }^{52}$, aunque fallecería nueve meses después a causa de la hepatitis contraída por las transfusiones de sangre recibidas. Este caso resultó la excepción, pues todos los intentos fracasaron al carecer de estrategias inmunodepresoras. Cuando Hume fue reclamado como cirujano para la Guerra de Corea, Joseph Murray, un cirujano plástico, fue nombrado encargado del programa de trasplantes. En 1954, Murray tuvo suerte. El primer trasplante de riñón con éxito total se realizó el día 23 de diciembre de aquel año. Donante y receptor fueron gemelos monocigóticos cuya identidad inmunológica había sido confirmada mediante injertos cruzados de piel. La intervención la realizó un equipo dirigido por Joseph Murray, en aquel mismo hospital ${ }^{53}$.

Ensayos clinicos en cáncer. En 1966, Charles Huggins recibió el Premio Nobel de Fisiología o Medicina por su descubrimiento, en la década de los años 1940, de la influencia de las hormonas en el cáncer, aunque otros cirujanos habian notado esta relación. En 1786, John Hunter había observado que la orquidectomía bilateral causaba atrofia de la próstata en animales ${ }^{54}$, efecto sobre el que insistió, en el año 1983, J William White, de la Universidad de Pennsylvania. White publicó, dos años después, su experiencia con la castración en 111 pacientes que habian tenido síntomas de hipertrofia prostática, indicando mejoría en 51 de ellos; aproximadamente, un tercio de los pacientes de White padecían cáncer de próstata ${ }^{55}$. La ooforectomía como tratamiento del cáncer de mama, por lo que se cita a Huggins con frecuencia, también se utilizó con anterioridad a su trabajo de $1942^{56}$. En 1896, George Beatson, de Glasgow, fue el primero en publicar que tal procedimiento provocaba la regresión de metásta$\operatorname{sis}^{57}$; efecto que fue, pronto, confirmado por otros. El estudio de Huggins -cirujano y especia- lista en urología, formado en la Universidad de Michigan, se trasladó a la Universidad de Chicago donde ejerció como cirujano y dirigió y trabajó en el Ben May Laboratory for Cancer Research- de las relaciones de los tumores respecto a la situación endocrina del organismo fue científicamente sofisticada y rigurosa y condujo a la comprensión de los receptores estrogénicos y al tratamiento moderno del cáncer de mama con inhibidores de esos receptores.

Con el antecedente de las puntillosas observaciones de Huggins y aunque el concepto de ensayo clínico controlado no parece que fuera con ellos, los cirujanos estuvieron entre los primeros en realizar ensayos multicéntricos a gran escala para comparar tratamientos de enfermedades humanas importantes. Desde los comienzos del siglo XX y bajo la influencia de Billroth, la práctica de la cirugía estaba gobernada por la anécdota y el prejuicio. Poco después del año 1950, los cirujanos fueron conscientes de que la aplicación del método científico podría ayudarles a diseñar ensayos clínicos por los que los resultados de diferentes operaciones podrian ser comparados. Henry Buchwald y Richard Varco ${ }^{58}$ establecieron, en 1963, un gran ensayo clínico para estudiar el efecto del puenteo entérico parcial sobre el metabolismo del colesterol, y Marshall Orloff59 inició, en aquel mismo año, una serie de ensayos clínicos controlados para estudiar pacientes con varices esofágicas sangrantes. Sin embargo, los ensayos clínicos más influyentes se ocuparon del tratamiento del cáncer de mama. Desde 1900 hasta 1970, los cirujanos siguieron el concepto de William Halsted de que el cáncer de mama metastatizaba, casi exclusivamente, por vía linfática; de ahí que la operación indicada era la extirpación del tumor primario, los músculos pectorales y los linfáticos regionales, en bloque: mastectomía radical. A finales de la década de los años 1950, Bernard Fisher, en la Universidad de Pittsburg, se replanteó tal suposición, proponiendo que no era posible separar el papel de los vasos sanguíneos del de los linfáticos en la extensión del cáncer de mama, y que las metástasis estaban gobernadas, en gran parte, por factores genéticos de las propias células cancerosas. Fisher, con la ayuda de los NIH, planteó, en el año 1971, los ensayos clínicos conducentes 
a evaluar los resultados de salud de pacientes con cáncer de mama avanzado y tratadas mediante mastectomía radical o por tumorectomía. Para gran sorpresa de la mayoría de los cirujanos, los amplísimos estudios controlados del National Surgical Adjuvant Breast and Bowel Project, que Fisher dirigió, demostraron que la tumorectomía e irradiación era tan eficaz que la mastectomía radical, en el tratamiento del cáncer de mama ${ }^{60}$. Desde entonces, bajo los auspicios del Colegio Americano de Cirujanos se realizan una serie de ensayos clínicos aleatorizados, prospectivos, en diferentes tipos de cáncer.

Investigación molecular. El número de enero de 1992 de la revista Archives of Surgery recogía un "comentario" de Edward Passaro que, con el título "Biología molecular: el mensaje, su lenguaje y el cirujano" comenzaba: "El mensaje está ahí, pero no es fácil leerlo. Simplemente está, y dice que la biología molecular preside el proceso del cambio fundamental de nuestros conceptos y del tratamiento de la enfermedad [...] La pena es que no son muchos los cirujanos que comprenden ese lenguaje, las implicaciones del mensaje, o incluso su papel en la conversación [...] Es cierto que mensaje tan profundo se ha escrito en un lenguaje arcano: cósmidos, YACs, centimorgan, RFLPs, telómeros o contigos no están en la jerga del cirujano [...] Pero de la misma manera que el cirujano necesita a la biología molecular, también la biología molecular necesita a los cirujanos [...] Los cirujanos tienen acceso a los tejidos humanos. En biología molecular tal acceso es crítico y sólo puede realizarlo el cirujano. No es una coincidencia que una parte de las investigaciones más imaginativas e incisivas en biología molecular del cáncer haya sido dirigida por cirujanos... Necesitamos conocer ese lenguaje [...] Necesitamos hablarlo. Ellos necesitan escucharnos" ${ }^{61}$. Al año siguiente, la misma revista iniciaba una serie bajo el título general "Cirujanos y biología molecular: una cohabitación feliz" ${ }^{62}$ para conmemorar el xL Aniversario del descubrimiento de la estructura del ADN. El editor de la revista escribia: "Clínicos y científicos básicos se necesitan unos a otros $[\ldots]$ La práctica quirúrgica de hoy está determinada por la investigación básica de ayer; mañana no será diferente. La mayoría de los departamentos de cirugía actuales comprenden la necesidad de que la biología molecular tenga una mayor presencia de en sus programas». Uno de los artículos de la serie llevaba el sugestivo título "¿Deben clonar genes los cirujanos?"63. "Los cirujanos están expuestos rutinariamente -scribian los miembros del Departamento de Cirugía de la Universidad de Pittsburg- a ciertos problemas clínicos, en la cabecera del paciente, ante los que sólo el cirujano está en condiciones de realizar preguntas relevantes". Así, han sido cirujanos quienes, contestando a esas preguntas, han hecho contribuciones relevantes al proceso de angiogénesis en el cáncer ${ }^{64} \mathrm{o}$ a la fisiopatología del sindrome de fracaso multiorgánico a través del concepto "tormenta citoquínica"65. También ha sido un cirujano -Thomas Starzl, quién puso en marcha el primer programa estable de trasplante de riñón primero, y de hígado después- el que ha impulsado la investigación de noqueo génico con el objetivo de producir animales concordantes para xenotrasplante; ello silenciando el gen de la gactosiltransferasa, responsable de los antígenos responsables del rechazo hiperagudo de los xenoinjertos $^{66}$. Y también ha sido un cirujano -Steven Rosemberg, National Cancer Institute en Bethesda, pionero en inmunoterapia, fue el clínico más citado en el mundo en el campo de la oncología, en el periodo comprendido entre 1981 y 1998- quién ha impulsado los programas más ambiciosos de terapia génica oncoterápica, fundamentalmente contra el melanoma ${ }^{67}$.

\section{LA INVESTIGACIÓN QUIRÚRGICA, CUESTIONADA}

En el número del 27 de octubre de 1983 de la revista $N$ Eng $J \mathrm{Med}$, se recoge la siguiente sentencia: «El año de trabajo en el laboratorio que aún forma parte de algunos programas de formación de cirujanos $[. .$.$] es una pérdida de tiempo".$ Lo firma el Dr. Robert Petersdorf, entonces Decano de la Facultad de Medicina de la Universidad de California, en La Jolla. Con tales augurios, porqué hacer investigación en un departamento de cirugia; ¿merece la pena el esfuerzo? Lo merece; primero por la misma razón que hace años los cirujanos se empeñaron en abrir las puertas al trasplante clínico o al tratamiento de los grandes traumatismos o a la alimentación parenteral total o [...] Otra razón es, 
simplemente, la curiosidad. Pero hay otra más importante; porque a lo largo del entrenamiento profesional, en cirugía especialmente, existe un punto especialmente débil: la dificultad de enseñar a los residentes cómo pensar de manera crítica y cómo evaluar resultados sin prejuicio. Es en el laboratorio donde se puede enseñar y aprender una actitud analítica rigurosa. Si un residente no hiciera más que eso, desprenderse del dogmatismo -sin publicaciones ni comunicaciones y sin que volviera por alli-, una estancia de unos cuantos meses y que decir de un año, tendría un valor inestimable en la formación de los futuros especialistas. "El arte de la cirugía es demasiado poderoso y demasiado peligroso para dejarlos en manos de un cirujano que sólo utiliza su cerebelo" ${ }^{40}$. Es imposible predecir si una investigación aportará valor añadido; pero si cirujanos e investigadores trabajan juntos la probabilidad incrementará.

Richard Horton pregunta68: "¿Cómo avanza el conocimiento quirúrgico?» Para contestarla, en parte, sirve una publicación ${ }^{69}$ que presenta los resultados de un estudio aleatorizado, que compara la colecistectomía realizada mediante laparoscopia o a través de una laparotomía reducida. El diseño de este estudio, que calcula el tamaño muestral adecuado, la aleatorización en el quirófano y el enmascaramiento de la técnica realizada (idénticos apósitos en los dos grupos de pacientes), establece un nuevo estándar para los ensayos clínicos quirúrgicos. La manera en la que los autores contestan a su pregunta -la cirugía laparoscópica no ofrece ventajas evidentes-, que puede influir en la práctica quirúrgica habitual, es más la excepción que la regla en la investigación quirúrgica. El estudio pone de manifiesto aspectos importantes sobre porqué investigan los cirujanos, cómo lo hacen, qué criterios utilizan para juzgar la validez de sus hallazgos y cómo su experiencia se compara con el resto de la comunidad médica. "Para tener una idea clara de lo que significa "investigación quirúrgica" escribe Horton- leí el primer número del año 1996 de nueve revistas de cirugía no especializadas ${ }^{70}$. En resumen, 215 artículos, de los que 175 presentaban los resultados de investigación original. Sólo 12/175 (7\%) mostraban datos obtenidos a partir de un ensayo clínico aleatorizado. E1 método de investigación más frecuente fue las series de casos (80 trabajos, 46\%); luego los estudios experimentales sobre animal de laboratorio $(31,18 \%)$. La importancia de las series de casos en cirugía está fuera de dudas, y parece razonable preguntar si puede confiarse en este método de estudio para obtener un resultado válido. Horton es tajante: "de acuerdo con el método epidemiológico convencional, la contestación es no".

Las ventajas de las series de casos son su bajo coste, rápidas de conseguir y fáciles de realizar; que generan hipótesis válidas para investigaciones posteriores y que, en ocasiones, aportan hechos distintivos que permiten, por ejemplo, definir nuevas enfermedades (sirva el ejemplo del sida $^{71}$ ). Sin embargo, las series de casos proporcionan las pruebas más débiles para valorar la eficacia de un tratamiento o para establecer una causa; algunos críticos ni siquiera las consideran investigación stricto sensu. Pero si la mitad de la investigación quirúrgica reside en las series de casos y si este tipo de estudio es el más vulnerable a la crítica, la lógica apunta a que una proporción significativa de las publicaciones en el ámbito de la cirugía tiene un valor cuestionable. Qué argumentos pueden esgrimirse para atenuar la preocupación sobre las series de casos. Aunque se acepta que los ensayos controlados aleatorizados son el estándar de oro para evaluar la efectividad de los tratamientos clínicos, quizás los cirujanos no contemplan tales estudios como una estrategia asumible para resolver problemas acerca del tratamiento quirúrgico; entre otros factores, porque la estandarización de las técnicas quirúrgicas es una de las mayores dificultades para diseñar protocolos aleatorizados.

¿Tendrá futuro la investigación en cirugía? Los cirujanos, hoy, no parece que contemplen esta cuestión como algo clave en su práctica. La competencia, el entrenamiento y la organización, parecen ser las principales preocupaciones. Pero si lo que domina son las series de casos, se deberían definir los estándares para publicarlas. Para mantener su reputación académica, los cirujanos deberian encontrar formas para colaborar con epidemiólogos a efectos de mejorar el diseño de las series de casos y plantear estudios aleatorizados. Además de estudios de seguridad y de eficacia, se necesitan estudios más pragmáticos para 
determinar la eficacia de las nuevas técnicas quirúrgicas con tratamientos estandarizados y bien contrastados. Desafortunadamente, la evidencia sugiere que la calidad de los estudios quirúrgicos es deficiente. En una revisión de 202 ensayos controlados aleatorizados en los que se comparan tratamientos quirúrgicos, la puntuación media fue de 0,40 en una escala de 0 a $1,0^{72}$. Conclusiones similares publicaron John Hall y Jane Hall ${ }^{73}$ tras evaluar 619 estudios clínicos quirúrgicos publicados entre enero de 1990 y diciembre de 1999: sólo el 33\% de los ensayos publicados $(202 / 619)$ presentaba un diseño válido. "Nuestro estudio indica -escriben- que la mayoría de los estudios quirúrgicos publicados ignoran aspectos básicos del diseño aleatorizado". Y otra publicación señala que la mayoría de los estudios quirúrgicos carecen, sobre todo, del rigor exigido a un ensayo de las características apuntadas $^{74}$.

Para obviar las deficiencias señaladas, el Clinical Epidemiology Group del Departamento de cirugia de la Universidad de Toronto, escribió una serie de trabajos sobre investigación en cirugia $^{75}$. "Las fronteras de la cirugía han avanzado con los años por una combinación de observación y de aplicación de la ciencia a problemas clínicos", decía la nota de los editores. "Hoy, la investigación en cirugía refleja el amplio espectro de la investigación en la ciencia médica, desde la genética y la biología moleculares a la aplicación de los ensayos clínicos aleatorizados para contestar a preguntas clínicas. Este notable crecimiento y vigor de la ciencia quirúrgica conlleva que la interpretación de los datos se haya hecho más compleja, lo que ha motivado que [Surgery] publique una serie de artículos cortos sobre la interpretación de los datos resultantes de la investigación en cirugía”. El primer artículo de la serie se ocupa de la "medición" en investigación clínica en cirugía ${ }^{76}$ : "Medir es la base de la investigación científica. Las medidas en investigación clínica en cirugía se utilizan para evaluar pacientes y los procedimientos y tratamientos que reciben. Además de las mediciones estándar de laboratorio, como la glucemia o los electrolitos en orina, los cirujanos suelen estar interesados en medir fenómenos complejos como la gravedad de una enfermedad, la disfunción de un órgano o la cali- dad de vida. Medir con precisión esos fenómenos clínicos complejos es uno de los retos de la investigación clínica en cirugía».

El panorama está en vías de cambio acelerado. La revista Surgery-Devoted to the art and science of surgery, publicación oficial de la Society of University Surgeons Norteamericana, una de las revistas de mayor prestigio en cirugía, viene incluyendo, desde la iniciativa antes citada, cada vez más numerosas aportaciones de investigación que distribuye en secciones muy específicas de la revista: Clinical research review, Evidence-based surgical hypothesis, Short research review, Surgical outcomes research o Surgical research review. Entre las diferentes modalidades, la "investigación de resultados en salud" (IRS) -outcomes- recibe atención creciente $^{77}$. La IRS se centra en la evaluación de la calidad y de la efectividad de la atención médica, a la vez que incorpora la perspectiva del paciente como el estado de salud percibido. Los resultados de IRS ayudan a conocer mejor las enfermedades y su tratamiento clínico y deben incorporarse en el proceso evaluativo de la efectividad de los servicios sanitarios con el objetivo de mejorar su calidad. Ello, hacia una "medicina basada en resultados en salud y como evolución lógica y deseable de la medicina basada en la evidencia " ${ }^{78}$. La IRS representa una amplia colección de metodologías en investigación en las diferentes facetas del sistema sanitario, cada una de ellas con distintas tradiciones y fundamentos científicos. Muchos estudios de IRS remedan a estudios de investigación clínica tradicional, con la que comparten algunos objetivos básicos: describir diferentes consecuencias de un tratamiento sobre los pacientes, identificar factores pronósticos y valorar la eficacia relativa de tratamientos alternativos. Ambos tipos de investigación pueden consistir en diseños experimentales (por ejemplo ensayos controlados y aleatorizados) o en estudios observacionales (series de casos, estudios de cohortes y estudios caso-control). A pesar de este solapamiento entre los estudios de investigación de las consecuencias de la atención médica y los estudios clínicos, las consecuencias se valoran a nivel de los pacientes, mientras que las tasas de las incidencias se refieren a los sistemas sanitarios o a las poblaciones asistidas. 
En resumen, los estudios sobre IRS se centran en aspectos concretos relacionados con el paciente. En efecto, la investigación sobre las consecuencias de la atención médica fue así denominada, porque se ocupa de hechos que son importantes para el paciente (por ej. nicturia, función sexual o continencia, tras prostatectomía) y no de los efectos del tratamiento sobre aspectos de la fisiología (por ej. flujo urinario). Los estudios de los pacientes, evaluados por métodos cada vez más complejos, cubren un amplio abanico de aspectos de la satisfacción del paciente y de su estado funcional ${ }^{79}$. Para ello, se dispone de numerosos indicadores para las diferentes patologias; por ej. el índice sintomático para pacientes con hiperplasia prostática benigna de la American Urological Association ${ }^{80}$. Sin embargo, son más utilizados aquellos que hacen referencia al bienestar físico, mental y social de los pacientes y que son valorados con datos genéricos, tales como el cuestionario 36-item Medical Outcomes $S t u d y^{81}$. Aunque relacionados con el estado funcional del paciente, estos indicadores (utilities) reflejan cómo se sienten los pacientes y cómo valoran distintos procesos asistenciales. Así, estos indicadores son expresiones cuantitativas de la calidad de vida y de las preferencias de los pacientes, y suelen combinarse con los indices de expectativa de vida para computar los años de vida ajustados a la calidad de ella (QALYs: quality-adjusted life years), un índice frecuentemente usado en análisis de decisión y en análisis coste-beneficio $^{82}$. Los indicadores suelen presentar una pobre correlación con el estado funcional o con los índices sintomáticos tradicionales; por ej. pacientes con índices sintomáticos similares por una determinada enfermedad discrepan en sus indicadores para los mismos síntomas. Junto con el tipo de estudios de resultados centrado en el paciente, otro tipo de ellos comparan la bondad de las actuaciones de los diferentes sistemas sanitarios -por ejemplo entre hospitales- y exploran las razones de las diferencias ${ }^{83}$.

Los estudios de resultados individuales rara vez son lo suficientemente robustos como para orientar decisiones clínicas. Incluso los estudios inteligentemente diseñados como los ensayos clínicos controlados y aleatorizados, dejan muchas preguntas sin contestar respecto a la eficacia clí- nica. Para afrontar tales problemas y añadir valor a la información proporcionada por los estudios individuales, el clínico dispone de dos herramientas principales: meta-análisis y análisis de decisión. El meta-análisis es una herramienta bioestadística para combinar y analizar conjuntamente los resultados de múltiples ensayos clínicos, si están bien hechos ${ }^{84}$. Y el análisis de decisión es una herramienta en auge para evaluar alternativas terapéuticas, y que la mayoría de los cirujanos contemplan como una "caja negra". Aunque pueden utilizarse para mejorar la toma de decisiones en un caso particular, se aplican generalmente para contestar preguntas clínicas genéricas (por ejemplo ¿en qué subgrupo de pacientes es eficaz la crioprostatectomía) y en evaluaciones económicas (por ejemplo ¿cuál es el coste-beneficio de la crioprostatectomía) ${ }^{85}$. Los sencillos árboles de decisión y los modelos de Markov representan los extremos de un abanico de modelos de análisis de decisión ${ }^{86}$.

A pesar de su amplia aplicación a la práctica quirúrgica, los cirujanos, en cuanto ejecutores de la acción médica, han tenido, en términos generales, un papel muy limitado en la modalidad de investigación de resultados de salud. Sin embargo, existen varias razones para lo contrario. Primero, los cirujanos deben responder al consumismo creciente de la asistencia médica; los pacientes reclaman información sobre las alternativas terapéuticas y su eficacia, a la vez de involucrarse, cada vez más, en la toma de decisiones (ver, en párrafos anteriores: cirugía endovascular y cirugía mínimamente invasiva). Muchos pacientes quieren conocer la competencia clínica y técnica de su médico, algo que en la actualidad y en determinados países -The U.S. Freedom of Information Act, FOIA- puede obtenerse de los medios de comunicación. El semanario Newsday publicó las tasas de mortalidad de cada uno de los cirujanos que realizaban revascularización miocárdica en el estado de Nueva York ${ }^{87}$. Los cirujanos, si participan en este proceso, podrán asegurar que los datos se toman adecuadamente y que se hacen los ajustes exigidos a la gravedad de la enfermedad antes de una difusión pública dificil de controlar a posteriori. Los cirujanos también necesitan responder a las administraciones, que atosigan con los costes y menos con la 
calidad. Quizás, lo más importante, es que los cirujanos tienen una obligación profesional de involucrarse en la investigación de resultados. Como científicos, los cirujanos tienen la responsabilidad de asumir el liderazgo de la evaluación de la práctica quirúrgica y de la aplicación de los resultados a la toma de decisiones clínicas. De esta manera, ayudarán a que la calidad asistencial no quede comprometida en el proceso del control de costes.

Francis Moore, en su conferencia presidencial de la Sociedad de Cirujanos Universitarios norteamericanos, en 1958, comentó: "En la cirugía académica existe un conflicto de intereses sin resolver [...] el conflicto entre el quirófano y el laboratorio $[. .$.$] entre la presión clínica y la aten-$ ción al paciente y la búsqueda de la ciencia. Pocos cirujanos académicos no han sufrido este conflicto. Aunque el cirujano universitario construye el puente entre el laboratorio y la clínica, los colegas que se sitúan a cada uno de los lados le espetan que no está en ninguno de ellos. Los científicos le reprochan no hacer la suficiente ciencia, y los cirujanos clínicos le acusan de que le faltan horas de quirófano. Es, por ello, un bastardo; y debe aprender a vivir con ello. Sin embargo, todos los avances de la ciencia quirúrgica desde Vesalio, Hunter, Lister, Halsted o Cushing se han hecho por aquellos que apostaron por adoptar tan incómoda postura ${ }^{88}$.

\section{EN RESUMEN, QUÉ ES INVESTIGAR EN CIRUGÍA}

La discusión de un caso clínico es la modalidad más sencilla de investigación clínica y tiene, por naturaleza, carácter educativo. La mayoría de ellos son simples observaciones fenomenológicas, pero en ocasiones cambian la práctica clínica por su relevancia clínica directa. Sirva de ejemplo la incidencia de un caso clínico, publicado por EJ Kosnick y WE Hunt ${ }^{89}$, sobre el tratamiento del vasoespasmo cerebral tras hemorragia subaracnoidea provocada por la ruptura de un aneurisma vascular. También, la investigación clínica aporta, frecuentemente, mejoras tecnológicas que inciden rápidamente en la práctica quirúrgica. Por ejemplo, la descripción de la cera para hueso por Victor Horsley, en 1892, permitió controlar fácilmente la hemorragia del hueso trabe- cular. La cirugía ortopédica y la neurocirugía hubieran progresado a duras penas sin esta sencilla técnica, que ocupó un cuarto de página en el British Medical Journa ${ }^{90}$.

Pero escudriñemos en las más complejas, pues ya quedaron reflejadas las series de casos o la IRS. Tras dos años de internado en el Hospital de Pennsylvania, donde se inició en protocolos de investigación clínica -efectos del cloruro potásico versus cloruro sódico en la dieta de pacientes con hipertensión severa-, John H Gibbon (19031973) se trasladó, en el mes de febrero de 1930, a la Facultad de Medicina de la Universidad de Harvard como research fellow en cirugia, integrándose en el laboratorio del Boston City Hospital dirigido por Edward Churchill, jefe del Harvard Surgical Teaching Service en aquel hospital. Churchill le indicó su primer trabajo de investigación: medir la presión en la arteria pulmonar con una fistula arteriovenosa femoral abierta y cerrada. Encontró que, con la fistula abierta, el incremento en la presión en la arteria pulmonar era muy discreto en comparación con el significativo incremento del flujo de sangre pulmonar, medido utilizando el principio de Fick. En junio de 1930, el Dr. Churchill se hizo cargo de uno de los servicios de cirugía del Hospital General de Massachussets; aquí, Gibbon se instaló en un laboratorio de investigación experimental situado en un viejo edificio. La idea de construir una máquina corazón-pulmón surgió en febrero de 1931 como consecuencia de las circunstancias que rodearon la muerte de una paciente a causa de una embolia pulmonar masiva. Durante la larga noche en que la paciente, cianótica, agonizó hasta morir tras practicársele una embolectomía pulmonar -ninguna operación de este tipo había tenido éxito-, Gibbon consideró la posibilidad de extraer sangre de sus venas distendidas, eliminar el $\mathrm{CO}_{2}$, oxigenarla y reinyectarla en las arterias de la paciente. En la primavera de aquel año, Gibbon contrajo matrimonio con Mary Hopkinson, auxiliar técnico del laboratorio de Churchill y retornó a Philadelphia, donde realizó su residencia en cirugía: tres años y medio practicando cirugía por las mañanas e investigación por las tardes. Con Eugene Landis - llegaría a ocupar la Cátedra de Fisiología en Harvard- estudió los efectos de la temperatura y 
de la presión tisular sobre el movimiento de fluidos a través de la pared de los capilares humanos. "Con frecuencia, mi mente -refiere Gibbon" ${ }^{91}$ se enfrascaba en la posibilidad de reemplazar temporalmente la función cardio-pulmonar por una máquina [...] Me di cuenta que aquel proyecto exigía tiempo completo, y mucho tiempo". Gibbon volvió con Churchill, quién no mostró interés por la posibilidad de un corazón-pulmón artificial, pero que nunca puso obstáculo alguno para su desarrollo. Menos entusiasmo aun mostró el gran amigo de Gibbon, Walter Bauer -llegaría a ocupar la Cátedra de Medicina en Harvard y a quién se hizo referencia en relación con la historia de la cortisona-, quién le indicó que si quería hacer una carrera académica en cirugía debería abordar proyectos menos ambiciosos, que pudiera publicar con rapidez en las revistas cientificas al uso e independientemente de los resultados. El único que mostró interés y le dio su completo apoyo fue Eugene Landis: "si crees que puedes hacerlo, merece la pena intentarlo". "No veía razón alguna -escribe Gibbon- por la que el proyecto no tuviera éxito; así que decidí hacerlo, a pesar de la completa ausencia de entusiasmo en los demás». En poco más de un año fueron Gibbon y su esposa, y el Departamento de ingenieria de Harvard- capaces de mantener hasta casi cuatro horas, con una rudimentaria máquina corazón-pulmón, las funciones cardio-respiratorias de gatos a los que se había ocluido la arteria pulmonar. Los resultados de esos experimentos fueron publicados en el año $1937^{92}$. En 1935, tras completar un año en Harvard, retornó a Philadelphia, continuando su trabajo en el Harrison Department of Surgical Research de la Facultad de Medicina de la Universidad de Pennsylvania. En 1939 los favorables resultados permitieron sugerir que "es concebible que una válvula mitral enferma pueda ser expuesta para su manipulación quirúrgica bajo visión directa, lo que ampliaría considerablemente los campos de la cirugía cardiaca y torácica». Continuó trabajando en aquel Departamento, ahora con una beca de la Fundación Josiah Macy. La Segunda guerra mundial interrumpió el trabajo. Tras cuatro años como cirujano del ejército retomó el proyecto en el Jefferson Medical College de Filadelfia. Era el momento de dar el paso definitivo. Gibbon se puso en contacto con Thomas Watson, presidente de IBM. "Nunca olvidaré mi primer encuentro con Mr. Watson en su oficina de Nueva York continua Gibbon-Llegó con todas mis publicaciones. Estrechó mi mano y se sentó a mi lado. Dijo que la idea era interesante y me preguntó como podia ayudarme. Recuerdo que le contesté balbuciente que no quería dinero por mi idea ni hacer dinero con ella. Me dijo que no me preocupara. Entonces le expliqué que lo que necesitaba era asesoramiento de ingeniería para el diseño y la construcción de una máquina lo suficientemente eficaz para utilizarla en pacientes humanos. Replicó: "De acuerdo. Dígame donde y cuando han de ir los ingenieros para discutir el proyecto con usted". Desde entonces, IBM no solo prestó todo el asesoramiento necesario sino que costeó la construcción de las sucesivas máquinas que permitieron progresar durante los siete años siguientes". El experimento decisivo tuvo lugar en abril de 1951; una de las máquinas consiguió mantener las funciones cardiorrespiratorias en un perro de 9,5 kg, durante $96 \mathrm{~min}$, con ambas venas cavas completamente ocluidas y con plena recuperación postoperatoria. El proyecto culminó el día 6 de mayo de 1953, con el cierre con éxito de un defecto septal interauricular en una paciente de 18 años de edad, que estuvo conectada a la máquina durante $45 \mathrm{~min}$ y siendo durante 27 min totalmente dependiente del aparato (Heart-lung machine Model II, IBM). Desde febrero de 1931 a mayo de 1953: veinte años tras una idea. Entre 1953 y 2007: innumerables pacientes beneficiados. ¡Esto es investigación quirúrgica! Y lo mismo es aplicable a válvulas cardiacas, prótesis articulares, marcapasos cardiacos y otros artilugios; todo ello conseguido a través de desarrollos tecnológicos, que han sido el resultado de colaboraciones entre la industria y cirujanos clínicos; una buena muestra de investigación traslacional ${ }^{93}$.

\section{EPÍLOGO}

Inmersos en pleno siglo XXI, es necesario mantener la capacidad de descubrimiento continuo en ciencias básicas. Pero sin una mayor preocupación por la clínica y por la prevención, no se lograrán los posibles beneficios de aquellos descubrimientos. La investigación proporciona los 
fundamentos de nuestro conocimiento científico; el reto del futuro será trasladar ese conocimiento para expandir las capacidades de la práctica diaria. Los centros académicos han de jugar un papel central para cebar una investigación básica a largo plazo que haga posible la innovación en el futuro; ello, potenciando la investigación clínica, lo que permitirá trasladar los nuevos descubrimientos a la práctica clínica, evaluar las prácticas clínicas actuales y contestar a lo que se debe y no se debe hacer en medicina: los pacientes son el comienzo del final de un proceso de descubrimiento ${ }^{94}$. "Si soy optimista -decía Abba Eban, diplomático israelí- es por la convicción de que los hombres y las naciones se comportarán con sabiduria, una vez que hayan agotado [y fracasado con] todas las demás alternativas " ${ }^{95}$. Como puede leerse en el vestíbulo del Centro Clínico de los NIH:

"Hospitals with traditions of excellence have demonstrated abundantly that research enhances the vitality of teaching, teaching lifts the standards of services, and service opens new avenues of investigation, ${ }^{96}$.

\section{Agradecimientos}

A las Doctoras $\mathrm{M}^{\mathrm{a}}$ Dolores Vigil Escribano y Amaya Sánchez Gómez, por su discusión y revisión crítica del manuscrito.

\section{REFERENCIAS}

1. Grillo HC. To impart this art: The development of graduate surgical education in the United States. Surgery 1999; 125 (1): 1-14. "Podré parecer arrogante, pero creo que puedo defender la premisa de que el sistema de residencia es, con mucho, el mejor método de formación de cirujanos". A ello sigue un comentario de SI Schwartz -The evolution of medical education; pp. 17-18- en el que puede leerse: "Los estudiantes de medicina son ahora "expuestos" a la medicina, en vez de formados en ella. Los residentes se han hecho funcionarios; mano de obra barata".

2. Thomas L. The youngest science: notes of a medicine-watcher. New York: Viking Press; 1983. Thomas L. Impact of managed care on medical education and research. Ann Surg. 1996;223(5):453-463.

3. Thompson JC. Impact of managed care on medical education and research. Ann Surg. 1996; 223 (5): 453-63. Un artículo de Basil A Pruitt -Combat causalty care and surgical progress. Ann Surg. 243(6):715-729;2006- ofrece una revisión detallada de la evolución de la práctica y de la investigación quirúrgica militar, y su impacto en la cirugía civil.

4. Angell M, Kassirer JP, Relman AS. Looking back on the Millennium in Medicine [Editorial]. N Engl J Med. 2000;342 (1):42-49.

5. Fischer JF. What we can and can't do: one surgeon's perspective. Bull Am Coll Surg 2001; 86: 19-23. Aunque nadie puede condonar los errores médicos, es desafortunadamente inevitable que se cometan errores en toda clase de actividad humana. Y aunque no existen pruebas que evidencien que los errores médicos puedan atribuirse a un exceso de trabajo de los residentes, la publicidad de aquellos ha sido la causa principal del recorte en el horario de los residentes, que quedó definido por el estado de Nueva York en 80 h semanales.

6. Kohn KT, Conegan JM, Donaldson MS. To err is human: building a safer health system. Washington DC: National Academy Press; 1999. Leape LL, Berwick DM. Five years after To err is human. What have we learned? JAMA 2005; 293(19):2384-2390.

7. Arky RA. The family business-To educate. N Eng L Med 2006; 354 (18): 1922-1926.

8. Thompson JC. Gifts from surgical research. Contributions to patients and to surgeons (2). J Am Coll Surg 2000;190(5): 509-521.

9. Swain JL. Is there room left for academics in academic medicine? J Clin Invest 1996;98(5):1071-1073.

10. Pierre Mendès-France (1907-1982). Político francés; ocupó el cargo de Primer ministro de Francia, entre 18 de junio de 1954 y el 23 de Febrero de 1955. Indira Gandhi (fue Primera ministra de India desde el 19 de enero de 1966 hasta el 24 de marzo de 1977, y desde el 14 de enero de 1980 hasta su asesinato el 31 de octubre de 1984) ante el Congreso de EE UU; Washington DC, 1982: "New knowledge is often the best way of dealing with old problems, we see our space effort as relevant for national integration, education and communication, and the fuller understanding of the vagaries of the monsoon which rules our economic life. Mapping from the sky also gives information about natural resources. Oceanography augments food and mineral supplies. Modern genetics open out vast possibilities... It is an inherent obligation of a great country like India, with its traditions of scholarship and original thinking and its great cultural heritage, to participate fully in the march of science which is probably mankind's greatest enterprise today". Indian Science Policy Resolution. India puso en órbita su primer satélite -Aryabhata- el día 19 de mayo de 1975.

11. El portaaviones "Principe de Asturias" tiene una dotación de 594 tripulantes y 29 aeronaves. Su comandante es un capitán de navio. Presupuesto anual: 26.020.090 €.

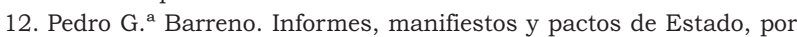
la Ciencia. Arbor 2004; 177 (698): ix-xliii. Frente a los "pactos de estado por la ciencia", reiteradamente firmados por investigadores -ipues faltaría más!- de nuestro país y sin otra firma de adhesión, los ejecutivos de dieciséis compañias americanas, líderes mundiales en tecnologia, firmaron un escrito urgiendo al gobierno a continuar su apoyo tradicional a la investigación básica y aplicada universitaria. El "anuncio" apareció en The Washington Post, el cinco de mayo de 1995, con el título "A Moment of Truth for America". En el texto puede leerse: "Imagine life without polio vaccines and heart pacemakers. Or digital computers. Or municipal water purification systems. Or space-based weather forecasting. Or advanced cancer therapies. Or jet airliners. Or disease-resistant grains and vegetables. Or cardiopulmonary resuscitation [...] This partnership-the research and educational assets of American universities, the financial support of the federal government and the real-world product development of industry-has been a critical factor in maintaining the nation's technological leadership through much of the 20th century. Just as important, university research has also helped prepare and train the engineers, scientists and technicians in industry whose discipline and skill have made technological breakthroughs possible. It has sparked innovation and prudent risk-taking. And as a result of the opportunity afforded such skilled workers in our technologically advanced economy, many disadvantaged young people have used high-tech jobs as a stepping stone to more productive and satisfying lives. Unfortunately, today America's technological prowess is severely threatened. As the federal government undergoes downsizing, there is pressure for critical university research to be slashed[...] For all these reasons, it is essential that the federal government continue its traditional role as funder of both basic and applied 
research in the university environment... As we reach the final years of the century, we must acknowledge that we face a moment of truth [...] As the Congress makes its decisions on university research, let there be no mistake. We are determining the 21 st century today". Ver: Tercera Encuesta Nacional de Percepción Social de la Ciencia y la Tecnología, realizada por la FECYT en colaboración con el Centro de Investigaciones Sociológicas; en: www.fecyt.es. Redacción. Percepción de la ciencia, ¿una paso atrás? SEBBM. 2007;151:26-28.

13. Webb J. HL Mencken quotation. En: www.io.com/gibbonsb/mencken/megaquotes.html.

14. Anderson RP. Change and thoracic surgery. J Thorac Cardiovasc Surg. 1992;103:186-193.

15. Walt AJ. Reflections. Detroit: Wayne State University Press; 1999.

16. Bush V. Science, the endless frontier. A report to the President [Franklin D Roosvelt] by the Director of the US Office of Scientific Research and Development. Washington DC: US Government Printing Office; 1945.

17. Watson JD, Crick FH. Molecular structure of nucleic acids: A structure for deoxyribose nucleic acid. Nature. 1953;171 (4356):737-738.

18. Kennedy TJ. James Augustine Shannon (1904-1994). En: http://books.nap.edu/readingroom/books/biomems/jshannon.pdf.

19. Bell JI. The double helix in clinical practice. Nature. 2003; 421:414-416.

20. Wyngaarden JB. The clinical investigator as an endangered species. N Eng J Med. 1979;23:1254-1259.

21. ASCI: American Society for Clinical Investigation. AAP: Association of American Physicians. AFMR: American Federation for Medical Research.

22. Gill GN. The end of the physician scientist? Am Scholar. 1984;53:353-368.

23. Glickman RM. The future of the physician scientist. J Clin Invest. 1985;76:1293-1296.

24. Goldstein JL. On the origin and prevention of PAIDS (Paralyzed Academic Investigator's Disease Syndrome. J Clin Invest. 1986;78: 848-854.

25. Goldstein JL, Brown MS. The clinical investigator: bewitched, bothered and bewildered - but still beloved. J Clin Invest. 1997;12: 2803-2812.

26. Coller BS. The physician-scientist, the state, and the oath: thoughts for our times. J Clin Invest. 2006;116:2567-2570.

27. Nathan DG. The several Cs of translational clinical research. J Clin Invest. 2005;115:795-797.

28. Feinstein AR. Basic biochemical science and the destruction of the pathophysiologic bridge from bench to bedside. Am J Med. 1999; 107:461-467.

29. Williams GH. The conundrum of clinical research: bridges, linchpins and keystones. Am J Med. 1999;107:522-524.

30. Rockey DC. The physician-scientist: a new generation or the last. J Invest Med. 1999;47(1):25-30.

31. Nathan DG. Careers in translational clinical research. Historical perspectives, future challenges. JAMA. 2002;287: 2424-2427.

32. Berzofsky JA. Cross-fertilization among fields: A seminal event in the progress of biomedical research. J Clin Invest 1994;94(9):911-918.

33. Thompson JN, Moscowitz J. Preventing the extinction of the clinical research ecosystem. JAMA. 1997;278(3):241-245.

34. Rock J. Conception in a watch glass. N Eng J Med. 1937; 217:678.

35. Swain JL. Is there room left for academics in academic medicine? J Clin Invest. 1996;98:1071-1073.

36. Arky RA. The family business - To educate. N Eng J Med 2006; 354(18):1922-1926.

37. Conter RL. The death of academic surgery? J Surg Res. 1998; 76(1):1-6.

38. Healy B. Innovators for the 21st Century. N Eng J Med 1988; 319 (16): 1058-1064. Healy desempeñaria la dirección de los NIH entre 1991 y 1993
39. Barker CF, Kaiser LR. Is surgical science death? J Am Coll Surg. 2004;198(1):1-19.

40. Souba WW. Reinventing the academic medical center. J Surg Res. 1999;81(2):113-122.

41. Churchill ED. Science and humanism in surgery. Ann Surg. 1947;126:381-396.

42. Folkman J. Surgical research: A contradiction in terms? J Surg Res. 1984;36(4):294-299.

43. Blalock A, Taussig HB. The surgical treatment of malformations of the heart in which there is pulmonary stenosis or pulmonary atresia. JAMA. 1945;128:189-202.

44. Carrel A.

45. Vorhees AB, Jaretski A, Blakemore AH. The use of tubes constructed from Vinyon "N" cloth in bridging arterial defects. Ann Surg. 1952;135:332-336.

46. Parodi JC, Palmaz JC, Barone HD, Álvarez A, Belardi J. Tratamiento con prótesis endoarterial de los aneurismas de la aorta abdominal. Rev Argent Cirug. 1990;59:228.

47. El tricorder es un sistema de registro múltiple utilizado por la Dra. Crusher en los USS Enterprise, en la serie de ficción Star Trek. Ver: Ministerio de Sanidad y Consumo - Instituto de Salud "Carlos III" Agencia de Evaluación de Tecnologias Sanitarias (AETS). Evaluación Epidemiológica de Tecnologias de Salud. Madrid: AETS - Instituto de Salud Carlos III, 1995. Ver: Tübke A, Ducatel K Gavigan J, Moncada Paternò-Castello P, IPTS. La información estratégica para la política: información sobre ciencia y tecnología para la toma de decisiones politicas. The IPTS Report 2003; 74: www.jrc.es/home/report/spanish/articles/vol74/MET1S746.htm: "Los resultados de la evaluación tecnológica facilitan la toma de decisiones, en materia de tecnologia, a través del análisis de las posibilidades sociales, económicas y medioambientales de los nuevos avances científicos y tecnológicos, lo que incluye sus impactos y sus circunstancias. A menudo, esto se basa en ejercicios previos de seguimiento de la tecnología. Con ayuda de la evaluación tecnológica se van desarrollando opciones para explotar mejor las oportunidades que brindan las nuevas tecnologías. La evaluación tecnológica puede incidir en una tecnología concreta (impulsada por la tecnología) o en los problemas de la sociedad que surgen cuando se aplica una tecnología (impulsada por el problema)".

48. Mühe E. Die ersie cholecystecktomie durch daas laparoskop. Langgenbecks Arch Klin Chir. 1986;369:804

49. Satava RM, ed. Cybersurgery: Advanced technologies for surgical practice. New York: Wiley; 1998. Taylor RH, Lavallée S, Burdea GC, Mösges R, eds. Computer-integrated Surgery. Technology and clinical applications. Cambridge MA: The MIT Press; 1996.

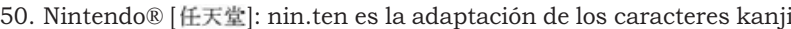
任天, algo así como "en manos del cielo" o "la responsabilidad en el cielo", y dō [堂], un sufijo común para nombres de negocios o laboratorios. En su origen, Nintendo es una marca registrada que identifica videojuegos avanzados.

51. Moore FC. Sketches of Dr Rhoads by friends. En: Barker CF, Daly JM, eds. Jonathan E Rhoads eightieth birthday symposium. Philadelphia: JB Lippincott; 1989. p.249-251.

52. Recogido en: Moore FD. Give and take: the development of tissue transplantation. Philadelphia: WB Saunders Co; 1964. pp.14-15.

53. Murray JE. The first successful organ transplant in man. Nobel Lecture (Dec 8, 1990), Les Prix Nobel, The Nobel Foundation, $1990 / 1991$

54. Welbourn RB. The history of endocrine surgery. New York: Praeger Publishers; 1990. p. 286.

55 . White JW. The result of double castration in hypertrophy of the prostate. Ann Surg. 1895;22:2-80.

56. Huggins C, Hodges CV. Effect of orchidectomy and irradiation on cancer of the prostate. Ann Surg 1942;116:1192-1200.

57. Beatson GT. On the treatment of inoperable cancer of the mamma: suggestion for a new method of treatment with illustrative cases. Lancet 1896;2:104. 
58. Buchwald H, Moore RB, Varco RL. Ten years clinical experience with partial ileal bypass in management of the hyperlipidemias. Ann Surg 1974;180(4):384-392.

59. Orloff MJ, Bell RH, Hyde PV, Skivolocki VP. Long-term results of emergency portacaval shunt for bleeding esophageal varices in unselected patients with alcoholic cirrosis. Ann Surg 1980;192 (3):325-337.

60. History of NSABP. En: http://www.nsabp.pitt.edu/Breaking Barriers.pdf.

61. Passaro E. Molecular biology: the message, its language, and the surgeon. Arch Surg 1992;127(1):15.

62. Organ $\mathrm{CH}$. Surgeons and molecular biology: A happy cohabitation. Arch Surg. 1993;128:1185-1186.

63. Geller DA, Billiar TR. Should surgeons clone genes? Arch Surg. 1993;128:1212-1220.

64. Folkman J. Clinical application of research on angiogenesis. N Eng J Med. 1995;333:1757-1763.

65. Aikawa N. Cytokine store in the pathogenesis of multiple organ dysfunction syndrome associated with surgical insults. Nipón Geka Gakkai Zasshi. 1996;97(9):771-777.

66. Phelps CJ, Koike C, Vaught TD, Boone J, Wells KD, Chen SH et al. Production of alpha 1, 3-galactosyltransferase-deficient pigs. Science. 2003;299:411-414.

67. Morgan RA, Dudley ME, Wunderlich JR, Hughes MS, Yang JC, Sherry RM et al. Cancer regression in patients after transfer of genetically engineered lymphocytes. Science. 2006;314(5796):6869.

68. Horton R. Surgical research or comic opera: questions, but few answers. Lancet. 1996;237:984.

69. Majeed AW, Troy G, Nicholl JP, Smythe A, Reed MWR, Stoddard CJ, Peacock J, Johnson AG. Randomised, prospective, single-blind comparison of laparoscopic versus small-incision cholecystectomy. Lancet. 1996;347:989-994.

70. Am J Surg, Ann R Coll Surg Engl, Ann Surg, Arch Surg, Br J Surg, Eur J Surg, J Am Coll Surg, Surgery y World J Surg.

71. Centers for Disease Control. Morbidity and mortality weekly report: Pneumocystis pneumonia. MMWR. 1981;30:250-252.

72. Solomon MJ, McLeod RS. Should we be performing more randomized controlled trials evaluating surgical operations? Surgery. 1995; 118:459-467

73. Hall JC, Hall JL. Randomization in surgical trials. Surgery 2002;132(3):513-518.

74. McLeod RS, Wright JG, Solomon MJ, Hu X, Walters BC, Lossing A. Randomized controlled trials in surgery: issues and problems. Surgery 1996;119(5):483-486.

75. Ballinger WF, Zuidema GD, eds. Editor's note. Surgery 1996;119 (3):241.

76. Wright JG, McLeod RS, Lossing A, Walters BC, Hu X. Measurement in surgical clinical research. Surgery 1996; 119(3):241-244.

77. Birkmeyer JD. Outcomes research and surgeons. Surgery 1998; 124(3):477-483.

78. Soto Álvarez J. Medicina basada en resultados en salud: la evolución lógica y deseable de la medicina basada en la evidencia. Med Clin (Barc) 2007;128(7):254-255.

79. Patrick DL, Deyo RA. Generic and disease-specific measured in assessing health status and quality of life. Med Care. 1989;27: S217-S232.
80. Barry MJ, Fowler FJ, O’Leary MP, Bruskewitz RC, Holtgrewe HL, Mebust WK, Cockett AT. The American Urological Association symptom index for benign prostatic hyperplasia. J Urol. 1992; 148 (5): 1549-1557.

81. Ware JEJ, Sherbourne CD. The MOS 36-item short-form health survey. I. Conceptual framework and item selection. Med Care. 1992;30:473-483.

82. Nord E. Methods for quality-adjustment of life years. Soc Sci Med. 1992;34:559-569.

83. O'Connor GT, Plume SK, Olmstead EM, Morton JR, Maloney CT, Nugent WC, Hernandez F, Clough R, Leavitt BJ, Coffin LH, Marrin, CA, Wennberg D, Birkmeyer JD, Charlesworth DC, Malenka DJ, Quinton HB, Kasper JF. A regional prospective study of in-hospital mortality with coronary artery bypass grafting. JAMA. 1991; 266:803-809.

84. Cook DJ, Mulrow CD, Haynes RB. Systematic reviews: Synthesis of best evidence for clinical decisions. Ann Intern Med 1997; 126: 376-380. Lau J, Ioannidis JPA, Schmid CH. Quantitative synthesis in systematic reviews. Ann Intern Med. 1997;127:820-826.

85. Birkmeyer JD, Birkmeyer N. Decision analysis in surgery. Surgery 1996; 120: 7-15. Birkmeyer JD, Welch HG. A reader's guide to surgical decision analysis. J Am Coll Surg 1997; 184: 589-595. Birkmeyer JD, Liu JY. Decision analysis models: Opening the black box. Surgery 2003; 133(1):1-4.

86. Ver: Birkmeyer y Liu para "learning more». pp. 3-4.

87. Zinman D. Heart surgeon rates: state reveals patient-mortality records. Newsday 1991; December 18:34.

88. Moore FD. The university in American Surgery. Surgery. 1958; 44:1-10.

89. Kosnick EJ, Hunt WE. Post-operative hypertension in the management of patients with intracranial arterial aneurysms. $\mathrm{J}$ Neurosurg 1944;1:58-59.

90. Horsley V. Antiseptic bone wax. Br Med J 1892;1:1165.

91. Gibbon JH. The development of the heart-lung apparatus. Rev Surg. 1970;27:231-244.

92. Gibbon JH. Artificial maintenance of the circulation during experimental occlusion of the pulmonary artery. Arch Surg. 1937;34: 1105.

93. Office of Portfolio Analysis and Strategic Initiatives. Re-engineering the Clinical Research Enterprise. NIH Roadmap for medical research. Bethesda, Maryland: National Institutes of Health, 2006. En: http://nihroadmap.nih.gov/clinicalresearch/index.asp.

94. Kohn LT, ed [Committee on the Roles of Academic Health Centers in the 21st Century-Institute of Medicine of the National Academies]. Academic health centers. Leading change in the $21 \mathrm{st}$ Century. Washington DC: The National Academic Press; 2003. En: www.nap.edu.

95. En: http://www.quotationspage.com/quotes/Abba_Eban.

96. La frase se debe a Jack Masur, promotor y primer director del Centro Clínico de los NIH.

Correspondencia autor: Dr. P. García Barreno

Real Academia de Ciencias

Valverde, 22 - 28004 Madrid

E-mail autor: pgbarreno@insde.es

Información artículo: Original 